\title{
FISCAL EQUALISATION IN AUSTRALIA: PROPOSALS FOR AN EFFICIENCY-BASED SYSTEM
}

\author{
by
}

\section{JEFFREY PETCHEY AND SOPHIA LEVTCHENKOVA*}

We argue that Australian equalisation should be driven by efficiency concerns. To this end, we propose an efficiency-based equalisation model and argue that, if implemented, this model would yield welfare gains in all States, relative to the status quo. Our model is also shown to yield superior welfare outcomes to an equal per capita allocation model (as proposed by some researchers to replace the existing model). The conclusion notes that given the magnitude of the resources involved, and the on-going concerns over equalisation, efficiency and equity, there is a case for a comprehensive and impartial review of the Australian grant system, including the equalisation methodology.

Keywords: Fiscal equalisation, Strategic behaviour, Local public goods, Labour mobility, Efficiency, Equity, Pareto.

JEL Codes: H21, H23, H41, J61.

\section{Introduction}

Taxing powers in the Australian Federation are highly centralised, mainly because the Commonwealth, through Section 90 of the Constitution, has exclusive access to the consumption tax base and, for various reasons, is the only level of Government to levy an income tax. On the other hand, expenditure responsibilities are relatively decentralised, with the States being responsible for major areas of service provision such as health, education, law and order, and roads. The Commonwealth, therefore, collects more taxation revenue than is needed for its own expenditures.

The resulting pool of surplus Commonwealth revenue-mostly from the GST-is distributed back to the States through the fiscal equalisation model employed by the Commonwealth Grants Commission (CGC). The key formula in this model is the one that determines the per capita grant to each State $\mathrm{i}:{ }^{1}$

School of Economics and Finance, Curtin University of Technology. We would like to thank two anonymous referees for helpful comments on an earlier draft. All errors remain, of course, the responsibility of the authors.

1 Where $i=1, \ldots . ., 8$ States and Territories in the case of Australia. Note that the formula used by the CGC also includes a term to deal with the budgetary position of each State. We abstract from these 


$$
\begin{aligned}
g_{i}=\frac{G}{N}+\frac{E}{N}\left(\gamma_{i}-1\right) & +\frac{T}{N}\left(1-\rho_{i}\right) \\
& \text { where } \quad g_{i} \text { is the per capita grant to State } i .
\end{aligned}
$$

$G$ is the pool of grant funds available.

$\mathrm{N}$ is national population.

$E$ is total expenditure of all States.

$\gamma_{i}$ is a cost disability for State $i$.

$T$ is the own-source tax revenue of all States.

$\rho_{i}$ is a revenue disability for State $i$.

One can see from the formula that State i receives an equal per capita share of the grant pool, $\mathrm{G} / \mathrm{N}$, which is then adjusted by the remaining terms. The first of these is the 'expenditure need' of the State, $\mathrm{E} / \mathrm{N}\left(\gamma_{\mathrm{i}}-1\right)$. When $\gamma_{i}>1$ the expenditure need is positive and tends to raise the State's grant above the equal per capita allocation, while if $\gamma_{i}<1$ the State has a negative expenditure need which tends to reduce its grant below the equal per capita amount. Similarly, $\mathrm{T} / \mathrm{N}\left(1-\rho_{\mathrm{i}}\right)$ is the State's 'revenue need'. If $\rho_{i}>1$ the State has a relatively high income and a negative revenue need, tending to reduce its grant. If $\rho_{\mathrm{i}}<1$ the State has relatively low income and a positive revenue need which acts to increase its grant.

Thus, the CGC's formula has two parts: an equal per capita part and an equalisation part made up of expenditure and revenue needs. Therefore, it is useful to think of the model as one in which each State receives an equal per capita share of the pool, adjusted by equalisation needs. The extent to which the needs adjustments cause the grant allocations to deviate from equal per capita amounts, can be seen from Table 1.

TABLE 1

EQUALISATION, AUSTRALIA, 2002-3

\begin{tabular}{lrrrrr}
\hline & \multicolumn{2}{c}{ CGC Distribution } & \multicolumn{2}{c}{ Equal per capita Distribution } \\
& \$m & $\%$ & \$m & $\%$ & $\begin{array}{c}\text { Difference } \\
(1)-(2)\end{array}$ \\
& \multicolumn{1}{c}{$(1)$} & & \multicolumn{1}{c}{$(2)$} & & -1243.6 \\
New South Wales & 7723.9 & 29.0 & 8967.4 & 33.6 & -1097.8 \\
Victoria & 5552.9 & 20.8 & 6650.7 & 24.9 & 207.4 \\
Queensland & 5236.9 & 19.6 & 5029.5 & 18.9 & -185.3 \\
Westem Australia & 2447.8 & 9.2 & 2633.2 & 9.9 & 596.7 \\
South Australia & 2641.6 & 9.9 & 2045.0 & 7.7 & 480.8 \\
Tasmania & 1118.6 & 4.2 & 637.8 & 2.4 & 90.3 \\
ACT & 519.6 & 1.9 & 429.3 & 1.6 & 1151.5 \\
NT & 1423.6 & 5.4 & 272.1 & 1.0 & 0.0 \\
Total (Pool) & 26664.9 & 100.00 & 26664.9 & 100.0 &
\end{tabular}

considerations in order to concentrate on the equalising component of the grant formula. (See Commonwealth Grants Commission (1999) for full mathematical details of the equalisation model.) 
Three States-New South Wales, Victoria and Western Australia-would be better off with an equal per capita allocation while all other States and Territories would be worse off. The latter benefit from fiscal equalisation because in aggregate their needs are positive, thus adding to their equal per capita allocation.

One of the major impacts of equalisation is that it creates large transfers of income between States. This is a consequence of the fact that what a State contributes to the equalisation pool $\mathrm{G}$ is unlikely to be equal to what it receives as a grant. Indeed, such redistribution is one of the major intended effects of equalisation and a source of much controversy.

The purposes of this paper are threefold. First, we provide a brief overview of the major equity and efficiency arguments for and against equalisation and in particular the inter-State transfers that result. Second, we summarise, in a non-technical fashion, the results of our most recent research on the efficiency of equalisation (as we show in the discussion, these results are new). Finally, we highlight the policy implications of this work and propose specific reforms to the CGC's equalisation model (these reforms have not been proposed before). The proposed reforms are assessed on efficiency and equity grounds, and compared with another reform often suggested, namely, to move to an equal per capita allocation model.

Our conclusion is that the existing equalisation system creates two inefficiencies, one related to the inter-State allocation of mobile labour, and the other to strategic behaviour by States. We then propose an alternative efficiency-based model that yields a fully efficient outcome and hence produces a welfare gain relative to the status quo. Key aspects of our proposal are:

(i) The existing grant pool should be allocated to the States and Territories on a purely origin basis (each State or Territory receives exactly what its citizens contribute to the pool through Commonwealth taxes).

(ii) Equalisation should be efficiency rather than equity based, requiring that new disabilities be designed to capture inter-State differences in fiscal externalities, economic rents, and any other factors that affect the distribution of mobile factors of production across regions in an inefficient fashion.

(iii) Inducements for strategic behaviour should be removed from the equalisation formulas by making standards used within the formulas exogenous.

Finally, we argue that if inter-State factor mobility is sufficiently high, as we believe is the case in Australia, then our reform proposal passes the Pareto test that no one is made worse off. Factor mobility ensures that the welfare gains are distributed between the residents of all States, whether they lose or gain grant funds as a result of the reforms. However, for this to occur there will need to be migration from States that lose grants funds to those that gain. Thus, economic activity in States and Territories that are recipients under the current scheme would fall relative to regions that are currently contributors. However, national welfare would be higher.

The outline of the paper is as follows. Section 2 presents the overview of the existing arguments for and against equalisation. This serves as a background for discussion that follows. Section 3 provides the non-technical discussion of our recent technical work on efficiency and equalisation. The policy implications and reform proposals are discussed in Section 4 and Section 5 concludes. 


\section{Overview of Arguments for and against Equalisation}

As a preliminary, it is useful to have some appreciation of the economic arguments for and against equalisation. A comprehensive discussion of all the arguments is not possible here (for such a discussion see Petchey and Walsh (1993)). Therefore, we present only an overview of the main ideas.

As in many other federations, Australian equalisation is motivated exclusively by equity concerns, namely, to equalise State fiscal capacities. This can be seen from the following official statement of the aims of equalisation:

States should receive funding from the Commonwealth such that, if each made the same effort to raise revenue from its own tax bases and operated at the same level of efficiency, each would have the capacity to provide services at the same standard (Commonwealth Budget Paper No. 3).

By attempting to equalise fiscal capacities through inter-State transfers it is thought that citizens of a federation with the same preferences and incomes can enjoy the same standard of State-provided public services with identical tax burdens regardless of where they live. A federation with equalised State fiscal capacities is one that, in principle, replicates the equity of a unitary system while at the same time providing the benefits of decentralisation. The fiscal capacity argument is based on Buchanan's case for equalisation put forward in a paper in 1950 and discussed in detail in Petchey and Walsh.

An economic efficiency argument for inter-State transfers and equalisation emerged in the early 1980s known as the 'efficiency in migration' case. The idea is that local public goods provided by States may generate fiscal externalities that benefit all residents of a State and that immobile factors of production in fixed supply may create economic rents. The location decisions of mobile capital and labour can be influenced by the presence of these location specific externalities and rents, with the result that migrant factors of production are allocated inefficiently across regions. It is argued that there is an optimal inter-State transfer that corrects for these distortions and establishes an efficient regional distribution of mobile factors. The important papers in this literature include Boadway and Flatters (1982), Myers (1990), Burbidge and Myers (1993), Mansoorian and Myers (1994), Petchey $(1993,1995)$ and Petchey and Shapiro $(2000,2002)^{2}$

Equalisation has also been criticised by academics on economic efficiency grounds using regional computable general equilibrium (CGE) models extended to include optimising State Governments and factor mobility. For example, Dixon, Madden and Peter (1993) use such a model to show that equalisation creates inefficient migration. Dixon, Picton and Rimmer (2002) also develop a regional CGE model, this time incorporating the notion of the 'flypaper effect', to highlight other efficiency costs of equalisation. Groenewold, Hagger and Madden $(2000,2002)$ undertake analogous work with CGE models to examine the general equilibrium effects of equalisation.

Swan and Garvey (1991) take a different approach by attempting to show that equalisation induces inefficient strategic behaviour by States. It has also been argued that equalisation may create 'transfer dependency', a particular issue for the Atlantic Provinces in Canada. ${ }^{3}$ In Australia, this may be an issue for some of the recipient States

For detailed analyis of these arguments also see Wellisch (2000). See Courchene (1984). 
where one could argue that equalisation slows down economic adjustments that would otherwise take place to facilitate inter-State income convergence, such as changes in relative wages between States or migration from low to high income regions.

The States have also criticised fiscal equalisation. A recent example is a review undertaken by Fitzgerald and Garnaut for New South Wales, Victoria, and Western Australia. This review was critical of equalisation on efficiency grounds and argued for an equal per capita allocation model. ${ }^{4}$ As one can see from Table 1, New South Wales, Victoria and Western Australia would benefit from an equal per capita model in the sense that their grants would be higher.

\section{State Strategic Behaviour}

A feature of the CGE analysis of equalisation, and much of the work on the efficiency in migration case noted above, is that the equalisation grant is treated as being exogenously given. In the CGE applications, the exogenous grant is varied to examine the general equilibrium effects of changes in grants to the States.

In practice the States do not treat their equalisation grant as exogenous to their decisions. Rather, they know that through the equalisation formulas their expenditure and tax decisions have an impact on other States as well as their own grant. This means that there is the potential for States to adopt strategic behaviour, that is, alter their policies in order to influence their grants, possibly at the cost of other States.

Our recent work, Petchey and Levtchenkova (2002), emphasises the potential impact of strategic behaviour on efficiency. The first step in this work was to develop a model of a two-State regional economy (thus, $i=1,2$ ) with location-specific economic rents, fiscal externalities (related to local public goods), factor mobility, optimising State governments, and a homogeneous population (which is also the labour force). The novelty of the approach is that we integrate the equalisation formulas into this traditional federalism model so that States take explicit account of the impact of their decisions on their grant. We think of the model as an 'equalisation game' in which the interests of the States are tied together through the equalisation formulas.

We have also constructed a numerical simulation version of the game. For given parameter values, we are able to solve the game for equilibrium values of important endogenous variables, including State public expenditures (State strategies), labour location decisions and migration patterns, State specific grants, and citizen welfare. Comparative static analysis can then be conducted by changing parameter values within the CGC's formulas, or the underlying structure of the formulas, and observing the effect of these changes on equilibrium values of the endogenous variables and in particular citizen welfare.

Any outcome of the game must also satisfy a condition related to factor mobility. In the most general case, one should allow for capital and labour mobility as well as the possibility that both factors may have some 'attachment to home', implying that they are only imperfectly mobile. So far in our modelling we have allowed for perfect labour

4 Papers prepared for the three-State review, directed by Fitzgerald and Garnaut, were published in the September 2002 issue of the Australian Economic Review. The results of the review, including the Report by Fitzgerald and Garnaut, entitled 'Commonwealth State Relations for the 21 st Century: Final Report', can also be accessed at the website http://www.reviewcommstatefunding.com.au. 
mobility (no attachment to home). This means that labour allocates itself across States in response to differences in wages and public good/tax packages offered by the States to satisfy an equal utility condition. Allowing for attachment would mean that in equilibrium there is some divergence between inter-State utilities for individuals with the same preferences and incomes. The extent of this difference will depend on the degree of attachment.

The model simulations yield the following results. First, we are able to replicate the standard result found in the efficiency in migration literature that there is an optimal transfer that corrects for the presence of fiscal externalities and rents. ${ }^{5}$ The second result is that the pattern and magnitude of inter-State transfers that emerge with the CGC formula in place are inconsistent with the ideal transfer. This is so for the following reason. From inspection of the CGC formula presented earlier one can see that the equal per capita component leads to implicit inter-State income redistribution (it transfers income from rich to poorer States). The needs component also results in inter-State transfers with the magnitude and direction of this redistribution being determined by the expenditure and revenue disabilities, $\gamma_{i}$ and $\rho_{i}$. But these disabilities are constructed on the basis of equity rather than efficiency considerations. Therefore, the redistribution supported by the existing disabilities is not motivated by fiscal externalities and rents: hence the inter-State redistribution that results from using the CGC formula is not efficient.

Finally, we show that the strategic behaviour induced by equalisation leads to 'under-provision' of public services in contributing States and 'over-provision' in recipient States, relative to efficient levels. The main reason is the presence of the terms $\mathrm{E} / \mathrm{N}$ and $\mathrm{T} / \mathrm{N}$ in the CGC formula. At present, these terms are endogenous and depend on collective State decisions on expenditure and own-source taxes. It is, therefore, these parts of the formula that are open to manipulation by the States in order to influence the size of the grant they receive. Our results here lend support to the idea of transfer dependency among recipient States discussed earlier. We would interpret transfer dependency to imply under provision of public policy in recipient States, including under-investment by such States in growth creating infrastructure.

The general conclusion is that outcomes from the equalisation game lie inside the Utility Possibilities Frontier (UPF) defined between residents of the two States. Since we have so far assumed perfect labour mobility the equilibrium must also lie on the 45 degrees line from the origin along which per capita utilities are equated across States for citizens of the same preference and income type. An efficient equilibrium with the optimal transfer implemented is at the point where the 45 degrees line cuts the UPF (a single point in utility space).

Se also identify here the cases where the efficient inter-State transfer is zero. They are: (i) if States are identical in terms of preferences, factor endowments and production technologies; (ii) if there are no distortions to location decisions; and (iii) if there is no mobility. Consistent with existing findings in the literature, we consider these to be very special cases and not to be of particular interest. 


\section{Policy}

These findings raise an obvious issue of interest to policy-makers, namely, how do we move from an inefficient outcome with the current formula to an efficient outcome? Two policy options are now considered.

\subsection{Equal Per Capita Allocation}

One option often touted, for example, by Fitzgerald and Garnaut, is to replace the existing model with an equal per capita allocation. ${ }^{6}$ This option has a simple appeal and could be achieved by deleting the needs component from Formula 1 so that the grant to a particular State is equal to $\mathrm{G} / \mathrm{N}$. If the pool for $2002 / 03$ had been allocated on this basis one can see from Table 1 what a difference this would have made to the grants received by each State!

Our modelling shows that this yields efficiency gains, relative to the status quo, but still results in an outcome that is inside the UPF (inefficient). The reason for this can be appreciated by noting that in moving from the current formula to an equal per capita model one removes the influence of the cost and revenue disabilities. This leaves a formula that, through an equal per capita allocation, still redistributes income from richer to poorer States. However, there is a correlation between such inter-State redistribution and the inter-State pattern of fiscal externalities that matter from an efficiency perspective. High-income States are likely to generate high fiscal externalities and low-income States are more likely to generate small externalities.

The equal per capita proposal, by redistributing from high to low income States, approximates this aspect of an efficiency-based transfer more closely than the existing formula. But because the correlation is imperfect the equal per capita allocation still results in an outcome inside the UPF. Thus, while an equal per capita allocation model yields an efficiency gain compared with the status quo we believe there is a better option, one that leads to a fully efficient outcome.

\subsection{Origin Grant with Efficiency-Based Equalisation}

The alternative we propose has four features. The first is to take the entire pool of funds G (presently distributed through the CGC formula) and allocate it to the States on an origin basis (the funds would be returned to the State or Territory in which they were collected). Such an allocation would have no effect on the inter-State distribution of mobile factors of production and would simply return revenue that is collected by the Commonwealth on behalf of the States because of the consumption tax restriction imposed by Section 90 of the Constitution (as noted earlier, this is largely GST revenue).

The second step is to recognise the need for an efficiency-based inter-State transfer (something that proposals for equal per capita allocations do not do)-in other words-acknowledge that there is a requirement for equalisation and a body such as the CGC on efficiency rather than equity grounds. A simple way to do this is to introduce a self-financing equalisation scheme where the inter-State transfer is driven by factors

6 These authors also propose that each State receive a minimum grant to contribute to the costs of government but basically their scheme is an equal per capita one. 
such as fiscal externalities and location specific rents that we know distort mobile factor location decisions. The scheme would be self-financing in the sense that the sum of funds to be taken from the contributing States is exactly equal to the sum of funds to be given to the recipient States. It could be implemented through a lump-sum transfer from contributing to recipient States. If a separate self-financing scheme is not feasible, then the efficiency-based equalisation scheme could be 'piggy backed' onto the origin based grants as they are returned to the States, in much the same way that equity based equalisation is piggy backed onto the current equal per capita allocation in Formula 1.

Third, the existing CGC formulas could be turned into the scheme proposed by; (i) deleting $\mathrm{G} / \mathrm{N}$ from the grant formula or turning it into an origin based component if the piggy back option is to be pursued; and (ii) changing the way that disabilities and needs are calculated. In particular, needs should be calculated to capture differences in the inter-State distribution of fiscal externalities, rents and any other factors that matter from an efficiency perspective (e.g. congestion costs). This would require extensive changes to the way that expenditure needs are estimated, in particular, the creation of new disabilities that capture factors that distort mobile factor location decisions, ${ }^{7}$ and the deletion of many other expenditure disabilities currently estimated by the CGC.

With regard to revenue disabilities, we believe the required changes may be minimal. This is because the revenue disabilities attempt to capture inter-State differences in income, and as noted these differences are likely to be highly correlated with inter-State differences in fiscal externalities. Indeed, one might even be able to leave the revenue need component of the formula much as it is on the basis that it is a reasonable proxy for fiscal externalities. This leaves the expenditure need component as the one most in need of change. One constraint here is that it might prove difficult to obtain empirical estimates of the factors that matter for efficiency, such as fiscal externalities. This is an issue that would need to be resolved through additional empirical research.

Finally, the new model should have no incentive for States to act strategically and distort their tax and spending decisions. One approach here is to make $E / N$ and $T / N$ in the formula exogenous variables, immune from manipulation by the States.

The origin-based aspect of the proposed model would return the fiscal gap revenue to the States without creating any mobility-related distortions. At the same time, there would be an efficiency based equalisation scheme that achieves the efficient degree of inter-State redistribution, and which is free of incentives to induce strategic behaviour by the States. With this approach, the amount of funds being redistributed between States would be much smaller than it is at present. From an efficiency perspective, it is superior to an equal per capita model because it addresses the need for an efficiencybased inter-State transfer in a clean and neat fashion.

\subsection{Equity: Would Pareto Approve?}

Would this reform pass the Pareto test that no one ibe made worse off, relative to the status quo? The answer is 'yes', if there is perfect labour mobility, even though some regions would lose grant funds. The reason is as follows. We know that in any outcome

7 An avenue to explore further here would be to investigate adopting a cost function methodology such as the one used by Petchey, Shapiro, MacDonald, and Koshy (2000). 
to the equalisation game labour mobility ensures that utilities are equal across States for residents of the same type. This must also be the case in any outcome with a grant system based on our proposal above, if there is perfect labour mobility. We also know. that an outcome to the equalisation game is inside the UPF and on the 45 degrees line where utilities are equated across States. However, an outcome with our proposed grant model is on the UPF (and the 45 degrees line) because there are no distortions-labour is allocated efficiently across States by the efficiency-based equalisation scheme, and there is no strategic behaviour (the UPF is a single point in utility space).

FIGURE 1

THE WELFARE EFFECTS OF ALTERNATIVE ALLOCATION MODELS WITH PERFECT MOBILITY

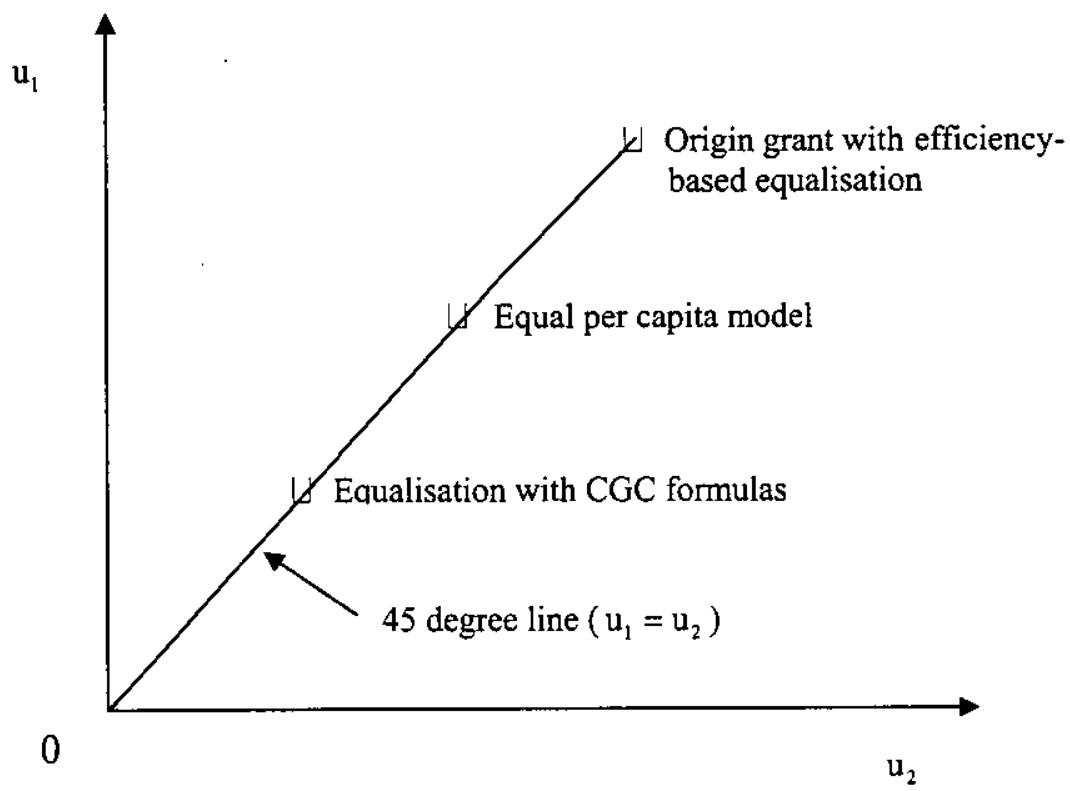

This is shown in Figure 1, where $u_{1}$ denotes the utility of a representative resident in State 1 and $u_{2}$ is the utility of a representative resident in State 2 (recall we have a two State model with homogeneous preferences). Clearly, the equal per capita model Pareto dominates the current CGC outcome but our efficiency-based model Pareto dominates both.

Therefore, our reform passes the Pareto test that no one is made worse off from the policy change. With perfect mobility and the $u_{1}=u_{2}$ constraint equity is 'built in' in the sense that migration ensures that the gains from the reform are distributed among all citizens of the Federation, regardless of their location. Of course, this requires that migration take place in response to the reform, and that there be fewer people in States that lose funds and more in those States that gain funds.

In Australia's case there is a high degree of labour and capital mobility between States (the Australian Federation has common internal markets for goods and factors of 
production) so it is likely that $u_{1}=u_{2}$ is a good approximation for reality. Therefore, we believe that factor mobility is likely to ensure that the Pareto test for our proposed reform is satisfied. But what if mobility is imperfect because of attachment to home? In this case (not yet incorporated into our modeling) our qualitative results still apply but in equilibrium there can be some divergence in utilities across States, depending on the degree of attachment (higher attachment implies greater divergence).

This possibility is illustrated for our two-State case in Figure 2. We now denote $\mathrm{N}$ as the outcome that results under the current CGC formulas (not necessarily on the 45 degrees line). Outcomes between (and including) $\mathrm{AB}$ Pareto dominate N. With sufficiently high immobility the outcome with origin-based grants and efficiency-based equalisation could be outside this range, though on the UPF. Hence, it is possible that reform could make one of the States worse-off. Mobility no longer ensures that the Pareto condition is satisfied. If decision-makers are constrained to implement only those reforms that meet the Pareto test, then it is possible that efficiency reforms to equalisation would not proceed if there is insufficient factor mobility to ensure that the gains are equitably distributed.

FIGURE 2

WELFARE EFFECTS OF ALTERNATIVE GRANT MODELS WITH IMPERFECT MOBILITY

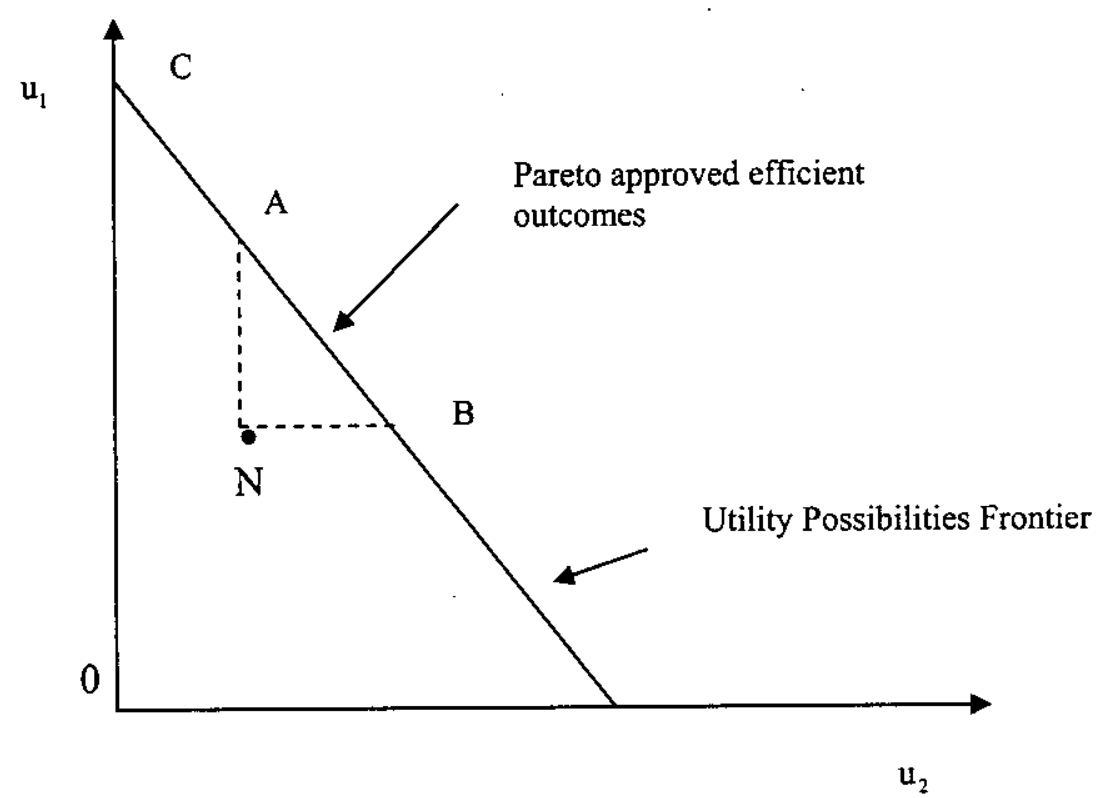

Decision makers might still proceed with reforms that result in outcomes outside the $\mathrm{AB}$ range using criteria other than Pareto, for example, a social-welfare function. For instance, it is possible to construct a social-welfare function which leads to a socialindifference curve that cuts an efficient outcome on the frontier between, say, C and A, and which yields higher social welfare than results at $\mathrm{N}$ (even though making State 2 
worse off). But there are well-known theoretical problems with social-welfare functions and there is the issue of what function to use (the choice will affect the results). Therefore, we prefer to apply the Pareto test to our reform proposal.

In addition, reform may proceed even if one of the States is ultimately made worse off, particularly if it is incremental and the adjustment pain is felt over a long period of time. There are examples of this in Commonwealth-State relations from the recent past. For example, over the last five years or so Western Australia has changed from being a recipient State to a contributing State with quite a significant relative loss of funds through the equalisation system. This process has been allowed to happen despite protests from the State (although admittedly, these changes have resulted from revised disabilities due to the State's rising natural resource wealth rather than from wholesale changes to the structure of the HFE model). ${ }^{8}$

\section{Conclusion}

Unlike some we see an important role for equalisation and the CGC but believe that equalisation should be driven by efficiency rather than equity concerns. An alternative grant model has been proposed in accordance with this preference for efficiency. We have argued that if implemented the model would yield welfare gains. Moreover, given that Australia has common factor markets with high inter-State factor mobility, we also believe that our proposal would pass the Pareto test: indeed, we have shown that the residents of all States would be better-off (though the allocation of mobile factors would be different with recipient States and Territories losing population to the rest of Australia). We have also argued that our proposal yields a superior welfare outcome to a simple equal per capita allocation model.

We conclude by noting that given the magnitude of the resources involved, and the on-going concerns over equalisation, efficiency and equity, there is a case for a comprehensive and impartial review of the Australian grant system, including the equalisation methodology. The review should not be undertaken by anyone with an interest in the outcome. It would, however, be appropriate for such a review to be conducted by a body like the Productivity Commission that has a long and credible track record in microeconomic reform issues. Given the inter-dependence between the grant system, the fiscal gap and tax assignment, it is sensible for such a review to include an examination of the efficiency effects of the current assignment of tax powers, and especially the potential for reforms to Section 90 of the Constitution.

\section{REFERENCES}

Boadway, R.W. and F. Flatters (1982) "Efficiency and Equalization Payments in a Federal System of Government: A Synthesis and Extension of Recent Results", Canadian Journal of Economics, 15, pp. 613-633.

Buchanan, J.M. (1950) Federalism and Fiscal Equity", American Economic Review, 40, pp. 583-599.

Buchanan, J.M. and C.J. Goetz (1972) "Efficiency Limits and Fiscal Mobility: An Assessment of the Tiebout Model", Journal of Public Economics, 1, pp. 25-43.

Could the Commonwealth make compensatory side payments to States that lose from reform in the sense that they lose grant funds? Compensation entails financial transfers to such States that simply reestablishes the pattern of inter-State transfers that caused the inefficiencies in the first place. This contradiction poses a potential barrier to using compensation to secure outcomes that Pareto dominate the status quo in the presence of substantial factor immobility. 
Burbidge, J.B. and G.M. Myers (1994) "Redistribution Within and Across the Regions of a Federation", Canadian Journal of Economics, 27, pp. 620-636.

Commonwealth Budget Paper No. 3 (2002-03) Federal Financial Relations (Canberra: Commonwealth of Australia).

Commonwealth Grants Commission (1999) Report on General Revenue Grant Relativities, Vol. II: Methods, Assessments and Analysis (Canberra: Commonwealth of Australia).

Courchene, T. (1984) Equalisation Payments: Past, Present and Future. Toronto: Ontario Economic Council, Canada.

Dixon, P.B., J.R. Madden and M.W. Peter (1993) "The Effects of Reallocating General Revenue Assistance Among the Australian States", Economic Record. 69, pp. 367-381.

Dixon, P.B., M.R. Picton and M.T. Rimmer (2002) "Efficiency Effects of Inter-Governmental Financial Transfers in Australia", Australian Economic Review, 35, pp. 304-315.

Fitzgerald, V and R. Garnaut (2002) "Commonwealth State Relations for the 21st Century: Final Report", http://www.reviewcommstatefunding.com.au.

Gramlich, E.M. (1984) "A Fair Go: Fiscal Federalism Arrangements", in R.E. Caves and L.B. Krause (eds), The Australian Economy: A View from the North (Sydney: George Allen and Unwin).

Groenewold, N., A.J. Hagger and J.R. Madden (2000) "Competitive Federalism: A Political Economy General Equilibrium Approach", Australasian Journal of Regional Stidies, 6, pp. 451-465.

Groenewold, N., A.J. Hagger and J.R. Madden (2002) "The Efficiency of Federal Inter-Regional Transfers Under a Regime of Politically-Maximizing Regional Governments", Department of Economics, University of Western Australia, Discussion Paper 02.03.

Levtchenkova, S. and J.D. Petchey (2001) "Recurrent Disabilities for the Australian States", School of Economics and Finance, Curtin University of Technology, Working Paper Series, 01.19.

Mansoorian, A. and G.M. Myers (1993) "Attachment to Home and Efficient Purchases of Population in a Fiscal Externality Economy", Journal of Public Economics, 52, pp. 117-132.

Myers, G.M (1990) "Optimality, Free Mobility and the Regional Authority in a Federation", Joumal of Public Economics, 43, pp. 107-121.

Petchey, J.D. and C. Walsh (1993) "Conceptual Foundations in Fiscal Equalisation" in Horizontal Fiscal Equalisation: Efficiency and Equity Issues in Historical, Political and Economic Perspectives. Submission to the South Australian Treasury by the South Australian Centre for Economic Studies.

Petchey, J.D (1993) "Equalisation in a Federal Economy with Inter-State Migration", Australian Economic Papers, 32, pp. 336-354.

Petchey, J.D. (1995) “Resource Rents, Cost Differences and Fiscal Equalisation”, Economic Record, 71, pp. 343-353.

Petchey, J.D., P, Shapiro, G. MacDonald and P. Koshy (2000) "Capital Equalisation and the Australian States", Economic Record, 7, pp. 32-44.

Petchey, J.D., and P. Shapiro (2000) "The Efficiency of State Taxes on Mobile Labour Income", Economic Record, 76, pp. 285-296.

Petchey, J.D. and P. Shapiro (2002) "State Tax and Policy Competition for Mobile Capital", Economic Record, 78, pp. 175-185.

Petchey, J.D. and S. Levtchenkova (2002) "The Welfare Effects of Fiscal Equalisation in a Federal Economy with Factor Mobility and Strategic Behaviour" Mimeograph, School of Economics and Finance. Curtin University.

Swan, P. and G. Garvey (1991) "The Equity and Efficiency Implications of Fiscal Equalisation", Swan Consultants Pty Ltd.

Wetisch.

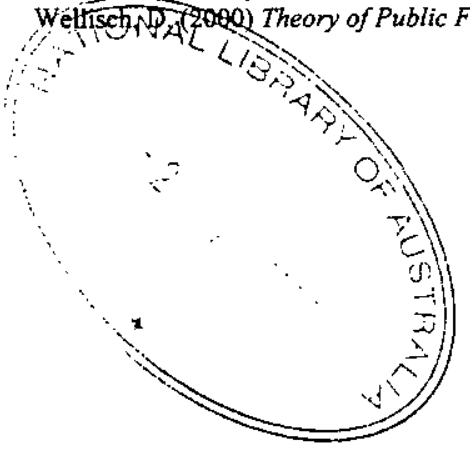

